\title{
LA YACENTE DEL ABAD DE OSEIRA FREY ARES DE SANTA MARÍA (SIGLO XV) $* 1$
}

\section{THE RECLINING OF THE ABBOT OF OSEIRA FREY ARES DE SANTA MARIA (15 ${ }^{\mathrm{TH}}$ CENTURY)}

\author{
Pablo S. Otero Piñeyro Maseda \\ Xosé Antón García GonzÁlez-Ledo \\ Miguel ROMANÍ MARTÍNEZ \\ CSIC-Xunta de Galicia \\ Instituto de Estudios Gallegos "Padre Sarmiento"
}

\begin{abstract}
Resumen
Del enterramiento de frey Ares de Santa María, abad de Oseira (1455-1485), sólo se conserva en la actualidad su yacija sepulcral con una inacabada inscripción. En las líneas que siguen, además de tratar sus aspectos artísticos y epigráficos, se ofrece una explicación de por qué no se concluyó, atendiendo a las noticias documentales disponibles.
\end{abstract}

\section{Palabras clave}

Escultura funeraria, abad cisterciense, epigrafía, vida cotidiana monástica, monasterio de Oseira.

\begin{abstract}
A grave with an unfinished inscription is what remains today of the burial of Brother Ares de Santa María (1455-1485), abbot of Oseira. Below we provide an explanation as to why the inscription could not be completed, by looking at the documentary information available, as well as considering its artistic and epigraphic qualities.
\end{abstract}

\section{Keywords}

Funerary sculpture, Cistercian abbot, epigraphy, daily monastic life, Oseira monastery.

\footnotetext{
* Este estudio es un resultado del proyecto titulado "Corpus de heráldica, escultura funeraria y epigrafía medieval gallega", que se desarrolla en el Instituto de Estudios Gallegos "Padre Sarmiento" (CSIC-XuGa) y del que es investigador principal el Dr. Eduardo Pardo de Guevara y Valdés, Investigador del CSIC.

${ }^{1}$ Entregado en Cuadernos de Estudios Gallegos el 26 de marzo de 2008.

${ }^{2}$ Profesor Titular del Área de CC y TT HH del Departamento de Historia I de la Universidad de Santiago.
} 
Frey Ares de Santa María ocupó la silla abacial del monasterio cisterciense de Santa María de Oseira, en San Cristovo de Cea, provincia de Orense, en los últimos meses del año $1455^{3}$. El cronista ursariense fray Tomás de Peralta lo nombra como "don Ares quarto, de sobrenombre Santa Maria, abad veinte y dos", situando cronológicamente el comienzo de su abadengo "mediado el iulio de 56" 4 . Su última mención documental como abad de Oseira data del mes de mayo de $1485^{5}$.

Varios autores han estudiado la yacente con inscripción inacabada que perteneció al monumento funerario del abad Ares o Arias ${ }^{6}$. En la actualidad se halla en la capilla de San Andrés, en el cementerio del monasterio ursariense. Nada se conserva de su yacija.

Los estudios más interesantes son los que analizan esta escultura funeraria desde el punto de vista artístico para datarla convenientemente ${ }^{7}$, pues con anterioridad -por no haberse percatado de que la inscripción estaba inconclusa- se databa erróneamente. El último autor que lo ha tratado en profundidad -Julio Vázquez Castro, repasando meti-

${ }^{3}$ En el año 1455 otorga su primera escritura como abad, aforando a Gonzalo de Veldrón el lugar de Aboldrón, en San Xoán de Camba, por seis cuarteros de pan puestos en la tulla de Santa Baya, otros servicios y vasallaje: véase doc. núm. 2714 de la Colección Diplomática del monasterio de Oseira, de próxima publicación.

${ }^{4}$ Véase Fray Tomás de Peralta, Fundación, antigüedad, y progressos del imperial monasterio de Nuestra Señora de Ossera de la orden del Císter, (Facs. de la ed. de Madrid, Melchor Alvarez, 1677), [Santiago de Compostela], Xunta de Galicia, Dirección Xeral de Patrimonio Cultural, [1997] (Patrimonio Cultural Galego. Fundamentos teóricos), pág. 229.

${ }^{5}$ Véase doc. núm. 3122 de la Colección Diplomática. Noticias y valoración del abadengo de frey Ares de Santa María, así como otras informaciones sobre su origen y trayectoria familiar en Pablo S. Otero Piñeyro Maseda, La documentación del monasterio de Oseira (Orense) 1435-1485. Estudio, edición e índices, Tesis doctoral inédita, Universidad de Santiago, 2008.

${ }^{6}$ El primero que dio noticia del sepulcro, tradicionalmente atribuido a un "obispo santo", fue el cronista Peralta en el año 1677, que como consecuencia de la lectura lineal de la inscripción del sepulcro, año de 1400, la ausencia de abad conocido entre los años 1368 y 1372, y ciertas dosis de fantasía, lo atribuyó a un supuesto don Arias III, "à quien pongo, y tengo por legitimo Prelado en lugar del intruso": véase Fray Tomás de Peralta, Fundación, antigüedad..., cit. en n. 4, págs. 206-210. Desde este momento se dio por probable -con ciertas reservas- la existencia de frey Ares III en distintas guías del monasterio y por parte de algunos investigadores, entre los que se puede destacar a Manuel LuCAS ÁLVAREZ, "Fray Alonso Yáñez de Mourigás, abad de Osera (1372-1414). Un intento de rectificación", en Miscelánea de estudios dedicados al profesor Antonio Marín Ocete, vol. 1, Granada, Universidad de Granada; Caja de Ahorros y Monte de Piedad de Granada, 1974, págs. 506-508; Manuel Chamoso Lamas, Escultura funeraria en Galicia: Orense, Pontevedra, Lugo, La Coruña, Santiago de Compostela, Orense, Instituto de Estudios Orensanos "Padre Feijoo", 1979, págs. 140-141; y Miguel Romaní MARTínez, "Abadologio y jerarquías del monasterio de Osera, siglo XIV", en Actas Congreso Internacional sobre San Bernardo e o Cister en Galicia e Portugal, 17-20 Outubro, 1991, vol. 1, Ourense, Xunta de Galicia; Deputación de Ourense, 1992, págs. 234-235.

${ }^{7}$ Véanse Julio VÁZQUEZ CASTRO, "El libro como almohada en la escultura funeraria", en El Mediterráneo y el arte español. XI Congreso Nacional del Comité Español de Historia del Arte (CEHA), Valencia 16-19 de septiembre de 1996, Madrid, Generalitat Valenciana, Conselleria de Cultura, Eduació i Ciència; Ministerio de Educación y Cultura, 1998, págs. 53-57; María Dolores BARRAL RiBADULLA, "La escultura funeraria medieval en el monasterio de Oseira", en Actas II Congreso Internacional sobre el Císter en Galicia y Portugal, vol. 3 (Arte), Ourense, Consellería de Cultura, Comunica- 
culosamente todo lo escrito sobre el asunto- ha dejado ya casi concluido el debate ${ }^{8}$, salvo que ignoró algunas observaciones históricas que se tratarán en las líneas que siguen.

\section{DESCRIPCIÓN DE LA YACENTE}

Del primitivo monumento funerario se conserva en la actualidad sólo la yacente, en la cual figura un personaje -con la cara muy erosionada- vestido con ropas de abad; la cabeza tocada con bonete, reposa sobre cinco códices en los que se detallan los nervios y herrajes de la encuadernación, y éstos, a la vez, sobre dos almohadas con sus borlas. En la parte izquierda, un ángel de rodillas y con parte del cuerpo mutilado. La mano derecha del personaje sostiene el báculo abacial con contera y la izquierda un códice; sobre el hombro izquierdo resalta una bien labrada venera. Mide 196 centímetros de largo, 76 de ancho por la cabecera y 53 centímetros por los pies, como ha podido comprobarse "in situ" en invierno de 2007 (figs. 1, 2 y 3).

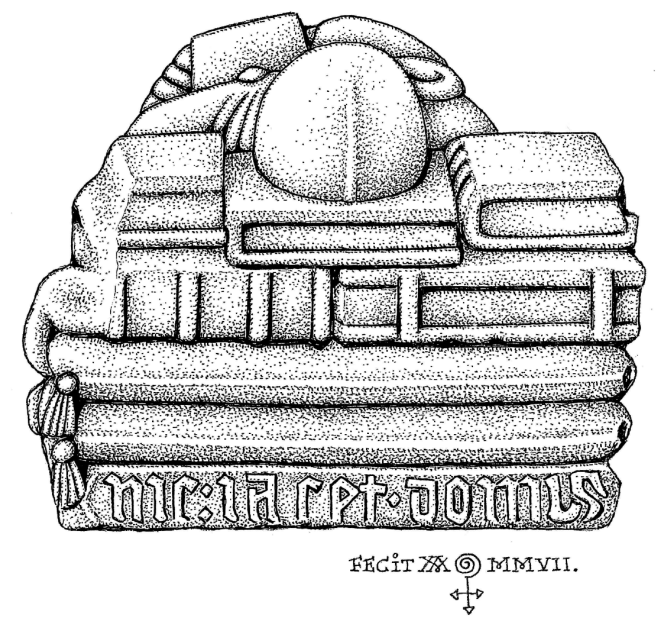

Figura 1: Testero de la yacente del abad frey Ares

ción Social e Turismo, 1998, págs. 1089-1090; y Lorenzo MARTínEZ ÁNGEL, "El uso de mitra por abades. Sobre el sepulcro del abad Arias de Oseira”, Porta da Aira, 9 (2002), págs. 293-296.

8 "Restituyamos la figura histórica del abad Alonso Yáñez de Mourigás pues si algún error cometió, y no fueron tantos como suponía Peralta, trescientos años de desprecio público ya han sido suficientes; desterremos de nuestros abadologios al abad Arias III El Ficticio pues nunca existió y devolvamos la propiedad del sepulcro conservado a su legítimo propietario, el abad Arias de Santa María, con su supuesto halo de hombre culto y su legendaria fama de santidad": véase Julio VÁzQuez CASTRO, "Fray Arias III, el abad «perdido» de Oseira", en Actas III Congreso Internacional sobre el Císter en Galicia y Portugal, vol. 2, Ourense, Xacobeo, 2006, págs. 935-960. 


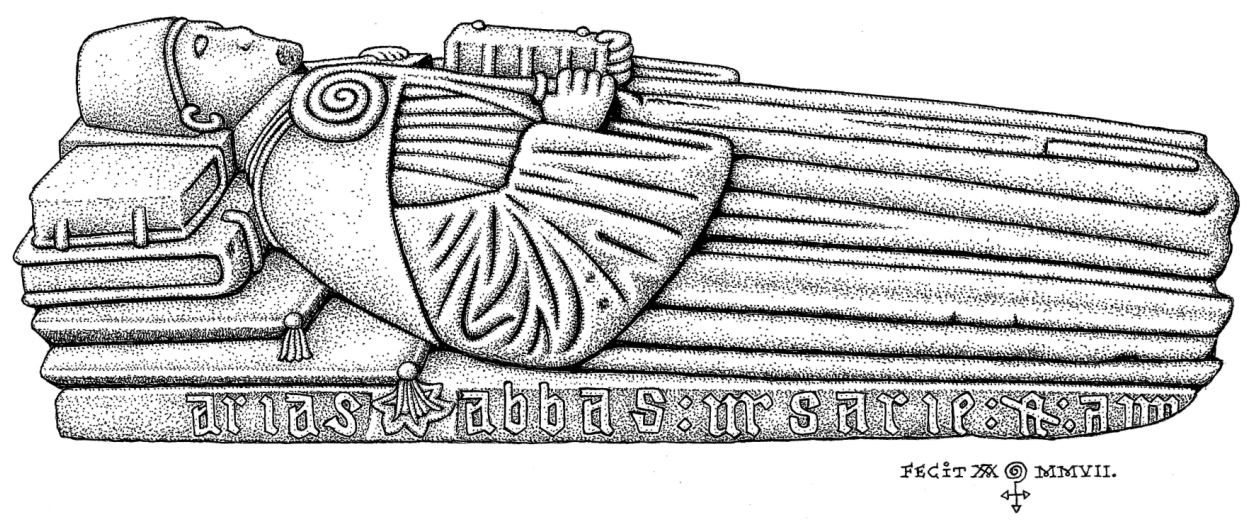

Figura 2: Parte derecha de la yacente.

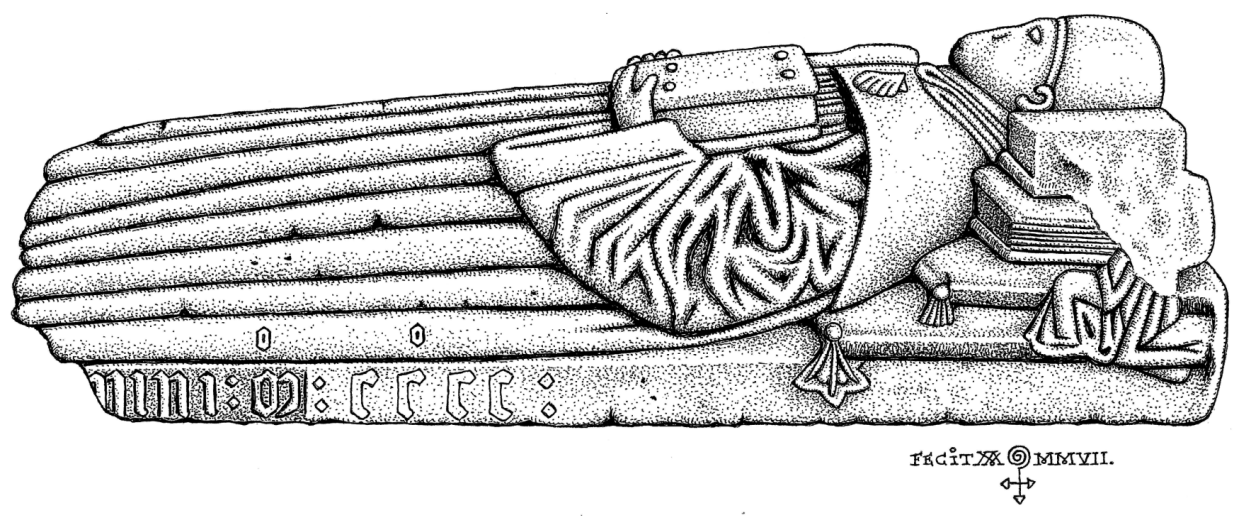

Figura 3: Parte izquierda de la yacente.

Al tener la yacente inscripción por todos sus lados, es de suponer que su emplazamiento primitivo estuviese destinado al centro de una capilla.

Bordeando el conjunto, empezando por el testero, en letra gótica resaltada salvo las cuatro últimas letras que están perfiladas -no en relieve como el resto de la inscripción sino sin terminar de labrar- figura la siguiente inscripción, que se cree incompleta al estar la yacija rota y faltarle unos cincuenta centímetros en la parte inferior de los pies:

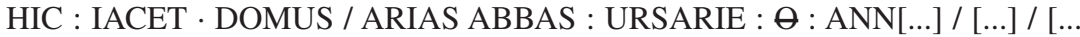
DO]MINI : $\mathrm{M}^{\mathrm{o}}$ : (letras perfiladas) $C C^{\circ} C C$ :

que quiere decir

HIC : IACET · DOM(n)US / ARIAS ABBAS : URSARIE : O(biit) : ANN[...] / $[\ldots] /\left[\ldots\right.$ DO]MINI: $\mathrm{M}^{\mathrm{o}}: C C^{\circ} C C$ : 
La parte inferior de la escultura se encuentra en la actualidad rota, lo que impide saber si los pies reposaban sobre el clásico animal o también -como en el caso de la catedral de Orense- sobre otros libros (fig. 4).

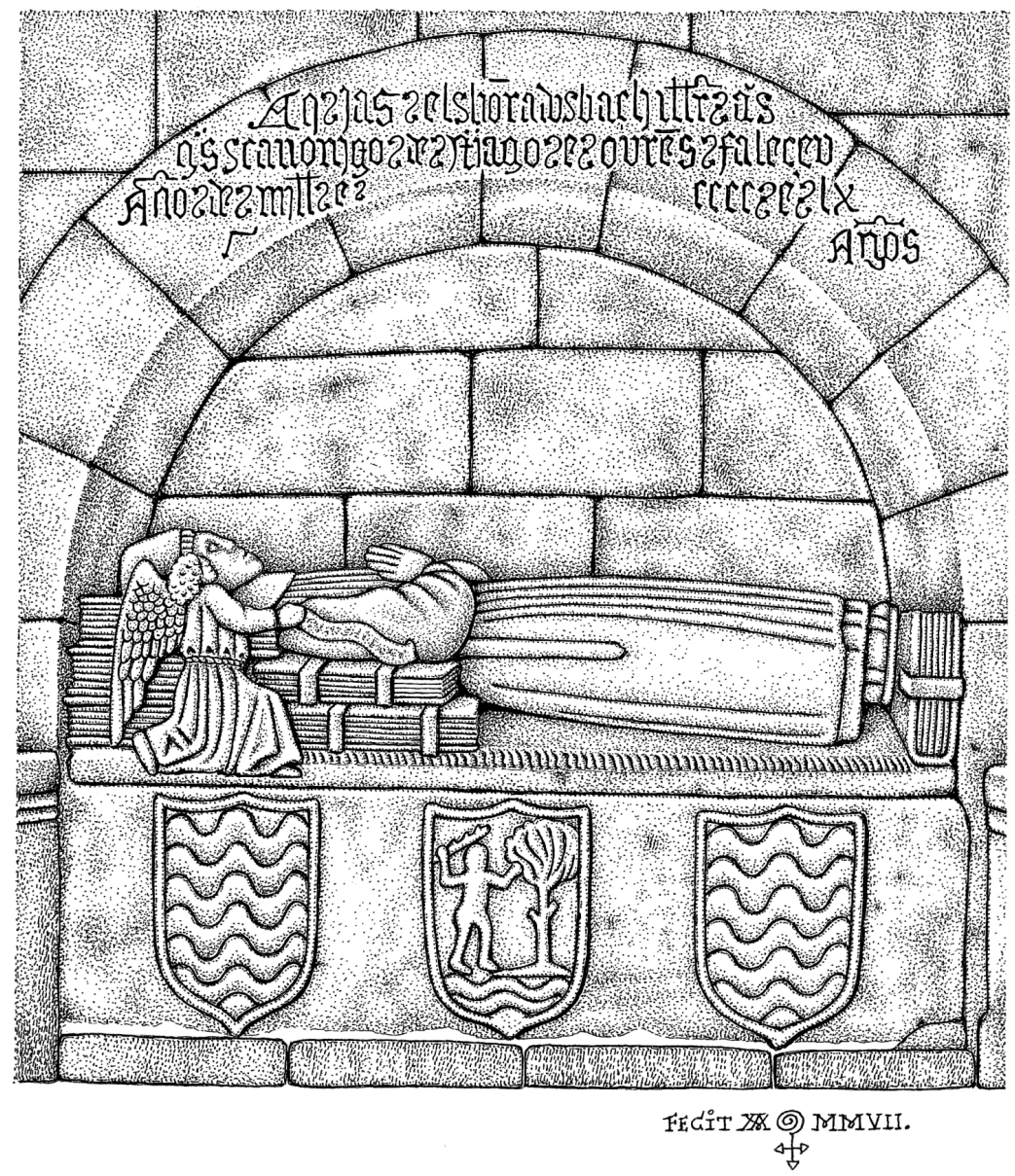

Figura 4: Enterramiento del bachiller Afonso González. 1460.

Contiene la siguiente inscripción:

AQ(ui) S JAZ S EL HO(n)RADO S BACHILL(e)R S

A(fons)O S //GS S CANONIGO S DE S S(an)TIAGO S E S

OURE(n)S(e) S FALEÇEU // AN(n)O S DE S MILL S E S /

CCCC S E S LX // AN(n)OS

Catedral de Orense.

${ }^{9}$ Sobre este personaje véase Anselmo LóPEZ CARREIRA, "Alfonso Gonçalves, un humanista no Ourense do século XV”, Porta da Aira, 4 (1991), págs. 191-196. 


\section{LA INCONCLUSA INSCRIPCIÓN: LA MARCHA DE FREY ARES DE OSEIRA}

Ninguno de los autores que identificaron la yacente como perteneciente al abad frey Ares de Santa María trató de documentar las posibles causas de por qué no se concluyó su epitafio o inscripción. En realidad, sólo advirtieron con acierto que "estaba inconclusa" 10 y que los últimos caracteres de la data "no aparecen perfilados"11.

Las informaciones publicadas por Ernesto Zaragoza Pascual arrojan luz a esta cuestión: frey Ares de Santa María no falleció siendo abad de Oseira; pactó su renuncia a la abadía ursariense con su sucesor frey Sueiro de Oca, futuro arzobispo de Tarso, con la siguiente condición: que frey Sueiro debía renunciar a su vez al priorato que disfrutaba de Santa Comba de Naves y entregarlo a Ares da Veiga, sobrino de frey Ares de Santa María ${ }^{12}$.

Estas noticias dadas a conocer por Zaragoza Pascual pasaron inadvertidas hasta el momento y son especialmente reveladoras: por un lado, ponen en cuestión la personalidad de frey Sueiro de Oca ${ }^{13}$, que antes de su llegada pactada a la abadía ursariense, había ocupado el priorato de Santa Comba de Naves (San Mamede de Palmés. Orense) desde el año 1481 siendo nombrado como frey Sueiro de Leborín ${ }^{14}$.

Por otro, que es lo que más interesa aquí, documenta que frey Ares de Santa María no falleció siendo abad del monasterio de Santa María de Oseira: negoció su salida de la abadía a cambio del puesto de prior en Santa Comba para su sobrino Ares da Veiga -clérigo por aquel entonces de San Payo de Castrelo (p. San Paio de Bóveda de Amoeiro. Amoeiro)- que posteriormente adoptaría el nombre de frey Ares de Santa María, homónimo de su tío; con el tiempo, sería este personaje el que

\footnotetext{
${ }^{10}$ Véase Julio Vázquez Castro, "Fray Arias III...”, cit. en n. 8, pág. 936.

${ }^{11}$ Véase María Dolores BARRAl Ribadulla, "La escultura funeraria medieval...”, cit. en n. 7, pág. 1090, siguiendo las precisiones de Julio Vázquez Castro.

12 Véase Ernest ZARAGOZA I PASCUAL, "Documentos inéditos sobre la reforma de los monasterios benedictinos gallegos (1496-1499), Estudios Mindonienses, 14 (1998), pág. 809 y docs. núms. 8 y 9 , págs. 825-832.

${ }^{13}$ La única biografía de este interesante personaje que bien merecería un estudio más ambicioso -fue además de prior de Santa Comba de Naves abad de Oseira, de San Esteban de Ribas de Sil, arzobispo de Tarso, deán de Orense y administrador del obispado- es de José GARCía Oro, "Don Suero de Oca (X-1513). El caballero. El abad. El arzobispo", Cuadernos de Estudios Gallegos, 23, fasc. 69 (1968), págs. 45-69; también documentos de interés editados por José García Oro, "Documentos sobre don Suero de Oca, Abad de Osera y Arzobispo de Tarso", Liceo Franciscano, 25 (Segunda Época), núms. 73-74-75 (1972), págs. 1-21.

${ }^{14}$ Posiblemente Leborín haga referencia al lugar de San Tomé de Barxa (Celanova). Véase Emilio DuRO PeÑa, "El monasterio de Santa Comba de Naves”, Anuario de Estudios Medievales, 5 (1968), pág. 160.
} 
resistiría denodadamente desde su priorato de Bande los intentos de anexión del cenobio, primero a San Pelayo de Antealtares y después a San Salvador de Celanova. Todo ello hasta el mes de marzo del año 1513, momento en el que Santa Comba se anexiona definitivamente a Celanova, de hecho y de derecho, por bula de anexión del papa León $\mathrm{X}^{15}$.

En las respuestas al interrogatorio de los testigos sobre la conducta de los priores de Rocas y Santa Comba en noviembre de 1498 que editó Ernesto Zaragoza, se documentan interesantes datos sobre frey Ares de Santa María, sobre su sobrino y sobre Sueiro de Oca: uno de los testigos declaró que "oyó dezir que el abbad que fue de Osera, el viejo, renunçió a la abbadía de Osera en don fray Suero, el obispo que agora es de Tarso, prior que a la sazón hera del dicho monesterio de Santa Conba para que el dicho don fray Suero renunçiase al dicho monesterio y prioradgo de Santa Conba en el dicho prior que agora hes del dicho monesterio, sobrino del abbad viejo de Osera"; otro testigo declaraba que "el dicho prior de Santa Conba ubo el dicho su monesterio que lo ubo por renunçiaçión de don fray Suero, obispo que agora es de Tarso, por quanto el abbad viejo de Osera, tío de dicho prior de Santa Conba renunçió en dicho fray Suero el su monesterio y abadía de Osera y le dieran dineros aun al dicho prior de Santa Conba que se viniese al dicho monesterio de Santa Conba. Preguntado cómo lo sabe, dixo que lo oyó a algunos de sus parientes del dicho prior y que es dello pública voz y fama". Otro dice que "el abbad viejo de Osera, que se llamava don Ares, renunçiara la dicha su abbadía en don fray Suero, obispo que agora es de Tarso, para que el dicho don fray Suero renunçiase en su sobrino Ares da Veyga, clérigo que era entonces de San Payo de Castrelo, el monesterio y prioradgo de Santa Conba que el dicho don fray Suero tenía"16.

Por el momento no se sabe a ciencia cierta qué interés tendría el abad frey Ares en renunciar a la abadía de Oseira -había mandado hacer en el monasterio su propio monumento funerario- en favor de frey Sueiro, a cambio de "colocar" a su sobrino en Santa Comba de Naves; dicho de otra forma, el "viejo" abad de Oseira no ganaba nada, al contrario, perdía mucho, y su sobrino -como declaró uno de los testigos- en realidad ya estaba "colocado" en el beneficio de San Payo de Castrelo (p. San Paio de Bóveda de Amoeiro. Amoeiro). Tampoco se sabe si tuvo algo que ver en todo ello el resto de la comunidad ursariense.

Las explicaciones a esta situación podrían venir de la pésima fama y conducta conflictiva de Ares da Veiga, sobrino del abad frey Ares, que pudo haber llegado al

\footnotetext{
15 Id. ib., págs. $160-165$.

16 Véase doc. núm. 9 en Ernest ZaRAgOZA i PASCuAL, "Documentos inéditos sobre la reforma...", cit. en n. 12, págs. 826-832.
} 
extremo de obligar a su tío a pactar la renuncia a la abadía ursariense a cambio de acceder él al cargo de prior de Santa Comba, o por el contrario, de la posición paternalista del tío respecto a su sobrino: los testigos coinciden en decir del prior Ares que en el año 1498 "es pública voz e fama que el dicho prior de Santa Conba mató un onbre acerca de la granja de Santa Cruz + da Rabaldo"; "que el dicho prior de Santa Conba que agora es mató un onbre en syendo clérigo"; "puede aver veynte años poco más o menos, que vio yazer un onbre muerto cabe Santa Cruz de Arabalde, y que dixeron que lo matara un clérigo de Vilamarín, que se llamava Ares da Veyga, y que es pública voz y fama que este fray Ares, prior que agora es de Santa Conba"; o que "el dicho prior de Santa Conba seyendo clérigo mató un onbre en la portilla de acerca de Santa Cruz de Arabalde" (Santa Cruz de Arrabaldo. Orense) ${ }^{17}$. A esto hay que sumar su conducta relajada y amoral, posiblemente habitual en aquellas fechas: "vio al prior que agora es de Santa Conba aver mançeba y dos hijas y un hijo"; "que vio andar en casa del dicho prior de Santa Conba una muger que se llamava Teresa de Treado, y que la casó con Gonçalo Denares, vezino de Ribadavia, y que le diera en fazienda y en dineros fasta na contía de diez mill maravedís poco más o menos y que esto pasara en Santa Conba"; "que vio en casa del dicho prior de Santa Conba andar un mochacho que se llamava Arisyno y que dezían que hera su hijo del dicho prior"; o que "vido al dicho prior de Santa Conba tener hijos y que oyó dezir que los ubo de una mançeba que tenía en casa de un su hermano"18.

Otros detalles de interés sobre el relajo de Ares, prior de Santa Comba, y de su homólogo de San Pedro de Rocas lo ilustran los testigos diciendo que "él vio a anbos los dichos priores andar a cada uno ençima de su caballo y traer espadas çeñidas y que algunas vezes los vio a pie con vallestas y con espadas çeñidas públicamente"; "que los sobredichos priores gastavan las rentas de sus monesterios con parientes y amigos y como ellos querían"; "que los vio dezir missa a los dichos priores y tener algunos monjes con ellos"; "que vio al dicho prior de Santa Conba thener un buen cavallo y andar ençima dél"; "que él vio a los dichos priores traher camisas de lienço y que vio al dicho prior de Santa Conba comer carne"; "que vio a un monje y a un capellán que servía dos yglesias, estar con el dicho prior de Santa Conba en su monesterio y que misa ninguna viera dezir al dicho prior"; "que los altares del dicho monesterio de Santa Conba estaban bien reparados"; "que cree que el dicho prior de Santa Conba deve de gastar con sus parientes parte de su renta e del dicho su monesterio, porque eran muchos parientes y pobles (sic) y muy acercanos dél”; "que vido al prior de Santa Conba tener a fray Alonso Salgado e a un

${ }^{17} I$ d. ib..

${ }^{18} I d . i b$. 
frayre coxo en su monesterio"; y finalmente, que "en quanto a lo de las bodas, que el testigo lo vido al dicho prior de Santa Conba en bodas públicamente" además de "que viera en el dicho monesterio de Santa Conba andar puercos en él, el monesterio no muy linpio"19.

Frey Ares de Santa María, a lo largo de su abadengo ursariense quiso perpetuar su memoria haciéndose labrar un vistoso sepulcro con unos libros o códices como almohada, y otro más en una mano quizá como recuerdo del "Libro Tumbo de Pergamino" por él promovido en 1473. Tan sólo faltaba esperar a su óbito para ser finalizada la inscripción sepulcral. Pero las cosas no salieron como él pensaba: tuvo que pactar con su sucesor su salida del monasterio. Y allí quedó su monumento, casi terminado, en el monasterio.

El cronista Peralta dice que antes de llevarlo a la "Iglesia vieja" estaba

"debaxo del primer arco (viniendo da la rexa) de la naue Colateral de la Iglesia, al lado de la Epístola [derecha], está pintada en la misma pared, que forma el arco vna Imagen de nuestra Señora, a cuyos pies es tradicion que antiguamente (y no muy antiguamente) estuuo vn sepulcro leuantado del suelo como media vara, que contenia en si el cuerpo de vn Santo Obispo, de donde al losar la Iglesia le quitaron. Y que la lamina que le cubria, es vna que oy se ve en la Capilla, ò Iglesia del Atrio, que llaman la Iglesia vieja"20.

Por lo que dice fray Tomás de Peralta parece entenderse que en la primera mitad del siglo XVII el sepulcro de frey Ares, con su yacija, estaba en un lugar "digno", y se desbarató poco después ${ }^{21}$ por un hecho trivial - una mejor pavimentación de la iglesia- trasladando su "lámina" o yacente a la que llamaban "iglesia vieja" o de San Andrés, donde actualmente se encuentra. Peralta, que era muy sagaz, escribió

${ }^{19} I d$. ib.. Quienes hacen estas declaraciones son cinco testigos, uno de ellos Pedro de Eiré, escudero, y todos ellos conocían al prior de Santa Comba de Naves y al de San Pedro de Rocas "de vista e conversaçión".

${ }^{20}$ Véase Fray Tomás de Peralta, Fundación, antigüedad..., cit. en n. 4, págs. 206-207.

${ }^{21}$ A este respecto, es interesantísima la reflexión del cronista Peralta, desgraciadamente todavía de plena actualidad: "Aun conoci yo, siendo muchacho, algunos ancianos, que assegurauan auer alcançado alli el sepulcro, malamente quitado, y mas, y letreros, que aora a retazos se vén por diferentes partes de la Casa, pero sin que en ello huuiesse mas malicia, que acaso el parecerles que quedaua poco hermoso el losado, no siendo todo en quadro, y menospreciando con poca curiosidad antiguallas, y memorias venerables, y si esto no (no hablo, aunque de passo sin causa, ni escuso el dezirlo), porque seria? Y si malicia, que fin en ella? Que perdia el Conuento en que se supiesse, que este Cauallero, ò el otro hidalgo estuuiese enterrado en su Iglesia, ò en su Cementerio? Niegosela yo ahora por ventura? Antes doy noticia de todos aquellos de quien la tengo": id. ib., pág. 207. 
que "estoy pensando, ò que no murió en casa, ò si murió, que no ocupó luego aquel sepulcro, sino que a él le traxeron (y esto se me haze mas probable) ò le trasladaron despues" 22 .

Con las últimas noticias documentales que ha facilitado la investigación de Ernesto Zaragoza lo más lógico es pensar que frey Ares de Santa María nunca se llegó a enterrar en su monumento; posiblemente quedó su sepulcro en el lugar donde menos estorbase a la comunidad, reutilizándose, y nadie se preocupó ni siquiera de terminar el epígrafe para que las generaciones posteriores supiesen el año exacto de su muerte ${ }^{23}$. Lo que consiguió frey Ares, sin embargo, fue perpetuar su memoria, aunque fuese desajustada a la realidad durante siglos, doblándose incluso su personalidad.

\footnotetext{
${ }^{22} I d$. ib., pág. 208.

${ }^{23}$ Por lo que parece, y como ya anticipó fray Tomás de Peralta, estos enterramientos no eran especialmente valorados en aquella época. Se documentó un hecho semejante en el pequeño monasterio de Santiago de Ermelo (Bueu. Pontevedra): en el siglo XVIII, el Padre Sarmiento ya advirtió allí que en una "losa [que] tiene dibujado un báculo" acaso estaría sepultado un obispo u arzobispo que "andando (...) a la visita, había muerto en Hermelo"; el Padre Sarmiento informaba también que ahora "sirve de sepultura común, pues está en el suelo, y habrá tres años que allí se enterró una vieja": véase Miguel Romaní Martínez y Pablo S. Otero Piñeyro Maseda, El antiguo monasterio de Santiago de Ermelo. Estudio, documentación e índices, Santiago de Compostela, CSIC; Xunta de Galicia, Instituto de Estudios Gallegos "Padre Sarmiento", 2005 (Cuadernos de Estudios Gallegos, Monografías, 6), págs. 37 y 52 .
} 